Visualizing Objects, Places, and Spaces: A Digital Project Handbook

\title{
Teams \& Expertise for Archival Projects
}

Beth Fischer, Hannah Jacobs, Claire Cahoon, Noah Huffman

Published on: Oct 14, 2019

DOI: $10.21428 / 51$ bee781.25dda8ce

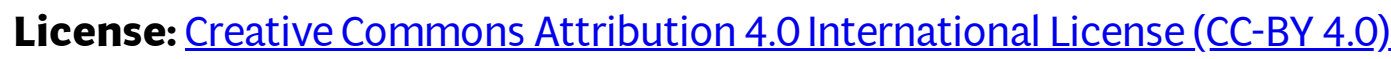




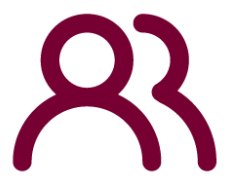

\section{The individual types of expertise you will need for a} project will vary, of course, and in many projects a single person will have more than one role. Frequently, individuals play these roles as consultants; for example, a small core team of content experts may consult a librarian or data science expert for help with the information architecture, or may hire a freelance person for help with some of the technological implementation. Even when working on highly collaborative team-based projects of people with similar skills, it is a good idea to spend time at the beginning of the project discussing how each of these roles will be filled and which roles each team member expects to play.

- A content expert: This is often the person who initiates the project. This role requires someone who knows the material well enough to identify errors, make decisions about the relative importance of different types of material, and decide how elements of the project relate to each other. In many cases, this person (or team) also writes summaries, introductions, and other interpretations of the archival content.

- An information architect: This is the person who decides how to break the content down into discrete elements and how to organize it. This role is often performed by the content expert, especially if the project is being run by someone with previous experience in museums or archives. If no one on the team has experience in this area, it is wise to consult an outside expert. Some academic institutions now have data services staff who can help; you can also ask a research librarian in your field; or consider consulting an archivist or registrar at an institution that works with similar materials. If no one is available and someone will be performing this role without previous experience, you can use other archival projects, museum collections, or even survey textbooks in the field to get a sense of how material is structured and what decisions you will need to make in this area.

- A database programmer: A database programmer can turn your raw material into a database or other structured system. In a project created in Excel, Airtable, or other basic spreadsheet-style program, this may be something that the content expert or information architect also takes on. In more complex archival projects, 
they will need an advanced skill set that may include things like SQL or php for connecting databases to searchable interfaces.

- Other possible skills or roles to consider: photographers, web designers, GIS mapping experts.

Continue reading: Budgets \& Funding for an Archival Project 